Abstract

\title{
Jatropha Curcas Development as Intervention Potential to Tackling Land, Energy and Food Challenges of Rural Communities in Dryland Sub-Saharan Africa
}

\author{
Joshua Ogunwole ${ }^{1}$, Gunnar Kirchhof ${ }^{2, *}$, Birhanu Z. Birhanu ${ }^{3}$, Sjoerd Duiker ${ }^{4}$ and Luiz F. Pires ${ }^{5}$ \\ 1 Bowen University, Iwo 232, Nigeria; ogunwolejo@hotmail.com \\ 2 School of Agriculture and Food Sciences, Faculty of Sciences, University of Queensland, St. Lucia, \\ QLD 4072, Australia \\ 3 International Crops Research for Semi-Arid Tropics (ICRISAT) West and Central Africa Hub, \\ Samanko 502 324, Mali; Z.Birhanu@cgiar.org \\ 4 Department of Plant Science, College of Agricultural Sciences, Pennsylvania State University, \\ University Park, PA 16802, USA; sduiker@psu.edu \\ 5 Laboratory of Physics Applied to Soils and Environmental Sciences, Department of Physics, \\ State University of Ponta Grossae, Carlos Cavalcanti 84030, Brazil; luizfpires@gmail.com \\ * Correspondence: g.kirchhof1@uq.edu.au \\ + Presented at the third International Tropical Agriculture Conference (TROPAG 2019), Brisbane, Australia, \\ 11-13 November 2019.
}

Published: 21 January 2020

\begin{abstract}
Global population growth is placing increasing pressures on land for food and feed production as well as energy security. In particular in sub-Saharan Africa (SSA), these issues require urgent attention. This is clearly stated in The United Nations Global Goals for Sustainable Development emphasizing the importance of sustainable use of land resources to increase food productivity and energy requirement. SSA lags behind most regions of the world in household food security and access to energy. The rural agriculture-dependent communities of SSA are the hardest hit by food and energy scarcity and the impact is felt most by communities in the dryland farming areas. In terms of energy supply appropriate measures and interventions are required to address this challenge. Jatropha curcas L. oil fast tracked itself from obscurity to prominence. Its main advantage is the high content of methyl ester (or bio-diesel). It conforms to EN 14214 specifications, exhibiting emission reduction potential and qualifying as a lucrative bio-diesel alternative to fossil diesel. This paper proposes a focus on Jatropha technology as a holistic approach to tackling the land, energy and food degradation challenges in unison for dry-land SSA. The new Jatropha strategy would be innovative and environmentally friendly soil resource recapitalization and supply feed stock for rural energy generation while fulfilling the criteria of delivering other benefits, such as addressing land use conflict for food and energy production
\end{abstract}

Keywords: land use; biofuels; agronomy; soil management

Funding: Part of this research was supported by the Legume \& Oil seeds Research Program at the Institute for Agricultural Research Samaru Zaria (Nigeria) and partly by the AfricaRise project of ICRISAT Mali.

Conflicts of Interest: The authors declare no conflict of interest.

(C) 2020 by the authors. Licensee MDPI, Basel, Switzerland. This article is an open access article distributed under the terms and conditions of the Creative Commons Attribution (CC BY) license (http://creativecommons.org/licenses/by/4.0/). 